Article

\title{
Legacy Planning and Event Sustainability: Helsinki as the 2012 World Design Capital
}

\section{Yi-De Liu}

Graduate Institute of European Cultures and Tourism, National Taiwan Normal University, Taipei 106, Taiwan; yideliu@ntnu.edu.tw; Tel.: +886-02-7734-3955

Received: 9 June 2018; Accepted: 11 July 2018; Published: 13 July 2018

Abstract: Sustainable events mean that the direct and indirect effects of events can be maintained. Planning legacy is becoming an important way to ensure the sustainability of events. Although the legacy of hosting major events is gaining interest among event researchers, a handful of empirical studies tried to discuss the articulation between event sustainability and legacy planning. This study contributes, therefore, to this line of enquiry. Based on the case of Helsinki as the 2012 World Design Capital, this paper aims to investigate the legacy plan of Helsinki, the perceptions of key stakeholders regarding the legacy outcomes, the determinants of legacy planning and its challenges. Methodologically, this paper is based on research conducted using a case study. The data collected are mainly qualitative and inductive in nature, supplemented by official documents and online resources. The study underlines that the integration of design into public administration, embedding design thinking, enhancing city image, reinforcing networking and the formulation of design policy are the main legacy outcomes. Also, the experience of Helsinki illustrates that legacy planning must consider three key factors-leadership in governance, communication with public, as well as timing and time, so as to create more sustainable longer-term effects.

Keywords: event sustainability; event legacy; legacy planning; World Design Capital; Helsinki

\section{Introduction}

Today, given the major economic, cultural, and social impact on host cities, there is fierce competition between cities to host major events. However, due to its ephemeral nature, events themselves may not be sustainable. For certain events, the programs might be reduced and the organising body might be dismantled soon after the event ends [1]. According to Holmes et al. [2], "the role of sustainability in events is becoming increasingly important and now features as part of the bid process for many mega-events... The idea of sustainability has permeated all aspects of society and is therefore an important consideration in event development" (p. 2). Sustainability of events refers to the continuation of the event activities and ensures that the direct and indirect effects of the events are sustained [1]. In this circumstance, legacy planning is a key way for guaranteeing the sustainability of events. Edizel [3] believes that legacy planning becomes a key component of sustainable event-led regeneration. According to Gratton and Preuss [4], there are three reasons that legacy or sustainability of events is getting more important: (1) providing evidence to win public support; (2) justifying the use of public resources for a temporary event; and (3) motivating other cities to bid for future events. Many cities have shown awareness of and commitment to legacy planning; however, the issue of securing events' sustainability remains complex and evidence of success is still scarce.

Designated every two years by the World Design Organisation (WDO), previously known as International Council of Societies of Industrial Design (ICSID), the World Design Capital (WDC) recognizes those cities using design effectively to promote economic, social, cultural, and environmental development. ICSID was founded in 1957 from a group of international 
organisations focused on industrial design. Today ICSID is a worldwide society that promotes better design around the world, and has since been renamed as WDO in 2017. Today, WDO includes over 140 member organisations in more than 40 nations. Previous WDCs have included 2008 Turin, followed by 2010 Seoul, 2012 Helsinki, 2014 Cape Town, and 2016 Taipei. Mexico City and Lille won the titles in 2018 and 2020 respectively. Through a yearlong event plan, cities are designated to demonstrate sustainable design-oriented urban policies and to innovate best practices for improving quality of life. [5]. The legacy of the WDC title on cities has become the focus of recent host cities. However, legacy planning beyond the WDC year varied considerably from city to city, given the levels of investment, especially from the public sector. In this context, the issue of legacy and sustainable impacts is critical, especially identifying good practice in event legacy planning and delivery. Based on the case of Helsinki as the 2012 WDC, this paper aims at addressing the following research questions: (1) what are the discernible sustainable effects connected with WDC? (2) how can the desired legacies be best planned and achieved? (3) what are the perceptions of key stakeholders regarding the legacy outcomes? and (4) what are the determinants of legacy planning? The following sections review the literature on event sustainability and legacy planning. In terms of methodology, both primary and secondary data were used. It is concluded by discussing the empirical and theoretical implications of this study.

\section{Legacy Planning and Event Sustainability}

"Growing emphasis on principles of sustainable urban development has focused greater attention on the social and economic legacy of events" [6] (p. 655). Considering event sustainability has to take into account the one-off nature of most major events; that is, some programs cannot be expected to continue and the level of activities are normally lower in the following years. Apart from the programs and activities, it is also necessary to consider the governance in the long-term. Furthermore, the sustainability of an event needs to be viewed from different dimensions. Several researchers, such as [1,2], pointed out that event sustainability could be examined in different dimensions, such as economic, social, cultural, political, and environmental. For long-term sustainability, host cities need to address all the different aspects of sustainability. For example, economic sustainability is not enough if the social or environmental aspects of an event are questioned [1].

To ensure event's sustainability, one major strategy is to develop holistic legacy plans. Event legacy can provide a justification for public expenditure, obtain local support, and encourage other cites to bid for events [7]. Several scholars have attempted to define legacy, for example, [4,8-10]. One popular definition of legacy was given by Preuss [10] as "legacy is all planned and unplanned, positive and negative, tangible and intangible structures created for and by a design event that remain longer than the event itself" (p. 211). Event legacies need to be planned, budgeted for, and worked at. They will not happen automatically or without intervention [2]. Sustainable legacy plan is an integral part of the planning for any major event and needs to be specific.

Although legacy planning is apparently a key element to sustain event's impacts, many practitioners admit that event's temporal nature remains a big challenge. The challenges may come from budget run out, the evaporation of political support or event organising staff being redeployed to new projects post-event. Holmes et al. [2] pointed out some strategies for successful event legacy planning. First, the legacy plan needs to be specific, realistic, and based on sound research and planning. Second, the event organisers need to ensure there are funds to deliver the legacy. One way is to incorporate the legacy plan into the original plans for the event or the bid document. Third, host community opinion and media reports need to be carefully managed as legacy plans take time to achieve their intended outcomes. A communication strategy is therefore necessary (for example, releasing regular positive new stories to keep the focus on the positive outcomes) so that the legacy plan won't be challenged immediately following the event. Fourth, a multi-theme legacy planning will have a broader appeal to the host community and attract wider media coverage. It could also be more effective at generating a longer-term impact. For the case of the WDC, there are some examples of 
planning for the future, particularly using the WDC as a platform to develop a design strategy that would survive the year. However, holistic plans for legacy after the event are still not widespread. In this context, research is therefore needed to investigate how a sustainable event could be achieved by successful legacy planning.

Although the legacy of hosting major events is gaining interest among event researchers, a handful of empirical studies tried to discuss the articulation between event sustainability and legacy planning. This study contributes therefore to this line of enquiry. For instance, Preuss [11] discussed the environmental sustainability of mega sport events and developed a framework for a green legacy. Gold and Gold [12] discussed the evolution of the Olympic movement's sustainability agenda, the relationship between sustainability and legacy, and the challenges encountered in implementing sustainability plans. Gaffney [13] examined the Olympic Golf project in Rio de Janeiro and explored the factors of un-sustainable event planning. Perić et al. [14] tried to identify the organisational challenges and analyse whether sustainable social and economic outcomes could be achieved, based on a case study of small-scale winter sport events in rural Croatia. Negruşa et al. [15] addressed the perceptions of cultural events' sustainability by analysing residents' perceptions on the economic, socio-cultural, and environmental impact of the International Film Festival. Koutrou et al. [16] explored the post-event volunteer legacy of the London 2012 Olympic Games. Liu [17] took the 2018 European Capital of Culture, Liverpool as an example to conceptualise the relationship between legacy planning and the long-term effects on community development.

\section{Methodology}

This paper is based on research conducted using a case study. The data collected are mainly qualitative in nature, including interviews and official documents, which help to yield evidence-based policy implications and recommendations. For the primary data, as this study focuses specifically on the perspectives of key stakeholders involved extensively in the 2012 WDC and the follow-up legacy plan, purposive sampling was adopted with the following 12 key informants.

- Head of Economic Development, City of Helsinki

- City Competitiveness, Economic Development, City of Helsinki

- City Marketing, Economic Development, City of Helsinki

- Secretary General, International Design Foundation

- Communications Director, DDC; Development Director, Visit Helsinki

- City Designer, DDC

- $\quad$ Founder/Director, Helsinki Design Week

- Executive Director, Design District Helsinki

- Head of Sponsorship, Design Museum Helsinki

- Professor Emeritus, School of Art and Design, Aalto University

- Head of Customer Services, Helsinki University Library

- Chief Executive Officer, Helsinki Business Hub

They are (or were) mainly based in the Department of Economic Development, City of Helsinki, International Design Foundation, and representatives from design industries in Helsinki. The first two are the guiding and executive bodies of the 2012 WDC and its legacy plan. The representatives of design industries come from Helsinki Design Week, Design District Helsinki, Design Museum Helsinki, Helsinki University, Aalto University, and Helsinki Business Hub. Interviews were conducted from 28 June to 15 July 2016. Each interview lasted for $47 \mathrm{~min}$ on average. Interview protocol was sent to the interviewees at least two weeks before the interview to ensure full understanding of the research topics. The interview protocol was developed based on emergent theories in the literature, and questions included: What are the major impacts of the WDC on the long-term development of the city? Has there been a sustainable platform for design-related events? What are the key elements of legacy planning of 
the 2012 WDC? To what extent WDC has an impact on increased cooperation among design industry? What lessons can be learnt from Helsinki in delivering the WDC effectively that might be of general applicability to other WDCs? As to the secondary data, online resources derived from City of Helsinki, International Design Foundation, and media reports were also referred to as supplementary data. In terms of data analysis, this study organised its findings into four main areas, including the content of legacy plan, the main legacy outcomes, determinants of legacy planning. Each of these thematic areas incorporates a series of sub-themes. In the analysis section below, the identities of respondents were protected by pseudonyms, shown as Interviewee \#1, \#2 etc.

\section{Helsinki as the 2012 World Design Capital}

Under the WDO's direction, the WDC Project is a biennial designation given to a city. The WDC is not only an event, but also a city development tool, which enforces design as a strategy in transforming the city and secures post-event legacy such as improvements in infrastructure and social-economic conditions [18]. The WDC designation is also a city promotion project that celebrates a city having used design as a tool to reinvent itself and to improve social, cultural, and economic life [19]. Finland is a country with a strong design tradition. Design is simply a part of the Finnish way of life. As part of the internationalisation strategy, Helsinki successfully held the 2000 European Capital of Culture with several annual festivals as a long-lasting legacy [18]. The influence of design on the city's development was first brought up in the 2009 city strategy. The strong emphasis on design culminated in 2012, when Helsinki was granted the designation of 2012 WDC by the ICSID. The bid not only emphasises the reach design legacy of Helsinki-with its famous designers and products-but also presents something new, which would also appeal to ICSID and help strengthen the WDC brand. The idea of WDC Helsinki 2012 "Open Helsinki-Embedding design in life" extends the concept of design from goods to services and systems [19]. One of the aims is to provide user-oriented municipal services and to strengthen residents' participation and responsibility. Other objectives are to make the city attractive, functional, and enjoyable; to create interesting, beautiful, and functional urban residential areas and environment; and to provide educational services that people need [20]. To sum up, WDC in Helsinki is not just about image but about intervening in everyday life, enhancing quality of life, boosting economic indicators, and raising awareness about the use of design in all aspects of urban development $[18,21]$.

The key theme of the 2012 WDC is the concept of 'Open Helsinki' that facilitates participation and involvement of designers and end-users in the co-creation of products and services that make cities better places to live [18]. The concept of an 'open city' highlights a new form of urban governance, in which top-down structures are at least partly replaced by bottom-up initiatives. It relates to popular concepts such as co-design (involving the community in designing places, products or service), design education (strengthening people's understanding of the importance of the design), and open data (sharing data to promote participation and to stimulate innovation) [19]. First, co-design implies that the demands and desires of the end-user have to be taken into consideration, not only in designing physical places but also in designing services [18]. Being the executive director of WDC Helsinki 2012, Pekka Timonen said in an interview: 'a design-driven city is a user-centric city' [22] (p. 10). Second, the WDC 2012 improved possibilities and tools to provide design education to children and youth in kindergarten and schools as well as through recreational activities. During the year, an estimated 50,000 children and young people participated in design education projects in Helsinki, Espoo, Vantaa, Kaunianen, and Lahti. It further strengthened Finland's status as a leading country in design education [23]. Third, open data is literally allowing for open and free access to public data. It is also an example of good cooperation in the region between municipalities and across sectors as well as with state government bodies. Making public information available will increase citizens' understanding of the development of their living environment. Transparency also improves citizens' involvement as the people have access to the city decisions and data resources concerning their everyday environment. Moreover, open access to information can also lead to new services and 
businesses, and it may advance research and development [19]. On the Helsinki Region Infosahre sites, more than 1000 sets of data have been published as public data in the Helsinki region, such as public transport schedules, geographic information, aerial photography, urban maintenance data, and so on. In late 2013, the public sector decision-making data were opened as well [23].

The programme of WDC Helsinki 2012 consists of 551 projects in 2800 events organised mainly in Helsinki, Espoo, Vantaa, Kauniainen, and Lahti, implemented by 14,500 people from 280 organisations. Altogether, WDC Helsinki 2012 projects reported 15,000 media hits both locally and globally [24]. The project can be divided into six categories: transforming the city, rethinking design, events, exhibition, encounters, and communications. WDC 2012 is a huge cooperation process between cities, residents, design organisations, universities, state offices, the private sector, and so on, who are devoted to using design as their creative power for transformation [19]. WDC 2012 is a joint effort of five metropolitan cities, including Helsinki, Espoo, Vantaa, Kauniainen, and Lahti. Aalto University and University of Helsinki play a crucial role as founding members of the International Design Foundation, which is the home of WDC Helsinki office. The support and funding from the National Government lay the solid ground for the process. Dozens of NGOs have joined the initiative. WDC Helsinki has also about 20 corporate partners supporting the process by 6 million Euros. Furthermore, the WDC brought together the international design community. Nearly 80 international seminars, conferences, and encounters were organised in the Helsinki metropolitan area [23]. As proposed by Holstila et al. [19], WDC Helsinki 2012 yielded four directions of impacts: (1) improving the organising incapacity of Helsinki; (2) making Helsinki as a city more attractive internationally; (3) encouraging city departments to adopt design methods and to make city smarter; and (4) improving the competitiveness of international and local companies based in Helsinki.

\section{The Legacy Plan of Helsinki}

The origin of having a legacy plan could be tracked back to the beginning of 2013 when the five mayors met to discuss the effectiveness of the 2012 WDC. They thought that the cooperation should last longer (Interviewee \#1). According to Pekka Timonen (previously Executive Director of 2012 WDC, Chairman of International Design Foundation, and Head of Cultural Office in the City of Helsinki), "once the WDC was over, the city of Helsinki had two options. One is to close everything and another is to remain a small organisation and a small project group making sure that some of the most important achievement of WDC could continue" [25]. Interviewee \#1 also noticed two key reasons of having a legacy plan. First, for most of the time, the investment in major event is only for the event year. The return on investment will be limited if the project ends right after the year. Second, something, such as grounding the design thinking, requires a longer period of time. Without a legacy plan, the investments are less likely to pay back. However, due to budget limitations, the legacy plan needs to be very focused. Explained by Pekka Timonen, with the successful implementation during the 2012 WDC, Helsinki decided to continue its focus on public service design. The legacy plan, called Design Driven City (DDC), was carried out by the main task force of WDC Helsinki 2012-the International Design Foundation [25].

Different from the WDC Helsinki 2012, which was an international appointment and a themed year of design with plenty of open events for a larger audience, DDC is primarily an initiative to develop cities with design methods, and a way to bring the public sector and the design field close to one another. The former mainly aims at promoting Helsinki internationally, while the latter seeks to firmly place design at the core of public service development and strengthen the user-oriented urban service design method [26]. However, the two projects both share the same bottom-line, namely using design widely in order to shape better cities. DDC has two concrete aims: (1) strengthening the use of design in city development initiatives and supporting these with know-how and expertise (DDC has its own design experts, called City Designers); and (2) educating the public sector on the significance of design, and participating in public discourse surrounding it [25]. Also, unlike other WDC cities, such as Seoul, which highlighted the 'hard legacy' (i.e., building up infrastructures), Helsinki decided to 
focus on the 'soft legacy', namely picking up some representative cases, which could be achieved firmly so as to ensure the effectiveness of project. Another consideration is again the budget. As explained by Interviewee \#2, hard legacy needs a lot more money and time. The budget for DDC is only $€ 1.5$ million and the administration and license around building is quite restricted in Finland.

Carrying on the development of design thinking and know-how within the planning of public services, the DDC lasted for two years (2013-2015) and was funded by four of five cities involved in the 2012 WDC (including Helsinki, Espoo, Kauniainen, and Lahti) and the central government [26]. With limited financial and human resources, DDC focuses on selecting projects that are representative and identified to be implemented so as to incorporate design thinking and enhance the effectiveness of project implementation. However, as the negotiation, fundraising, and recruitment took several months, DDC set out officially in early 2014 (Interviewee \#3). To provide expert design services for cities, the DDC project hired three city designers. City designers and city staff worked side by side in the process of urban development. The former helped the latter to deepen their understanding of citizens' needs and encourage residents to play a more active role in city decision-making and development. The task of the city designers is to determine the areas where the design can be applied and determine the method of applying the design in these areas [23]. To sum up, the DDC project emphasised the involvement of design in public sector and then improved public services. In the space of two years, development projects were chosen with the potential to bring design methods to new contexts and reach next-level outcomes through design. The major design projects achieved include creating new concepts for youth housing, improving library services, modernizing the city art museum, designing a citizen service centre, tidying up construction sites, developing school dining from the student perspective, supporting entrepreneurs in developing their business ideas, and helping develop a festival park where citizens meet [25].

During the field research, several interviewees talked about the most successful projects of DDC. First, 'Home that fits' is widely believed to be the representative initiative, especially from the public's point of view. In Helsinki, more than 1000 people under the age of 25 do not currently have regular residences. Since a young man seeking housing is often oppressed by bureaucracy, the solution can only be found by experimentation and changing the logic of the system. 'Home that fits' used design methods to investigate how vacant space can be converted into housing and how young housing can improve the entire community. Ministry of Youth of Helsinki, DDC, a non-profit leasing company, and the National Youth Housing Association worked together for this project [27]. From the publicity's point of view, 'Home that fits' is especially successful. According to Interviewee \#2, "how design-led thinking was implemented into the project isn't the key success. The key was thebreakthrough in the media, and in the public and also in the international press". The project attracted a lot of media attention simply because homelessness is a social, and even security, problem. Furthermore, the youth department very skillfully used social media and the news so as to make the issue public (Interviewee \#2). Finally, the project was widely reported by ABC, BBC, and Australian, Polish, and Taiwanese TV programs. The success of 'Home that fits' also lies on its efficiency. As said by Interviewee \#4, "the task is amazingly big, and we have to analyse what kind of resources we have, and we didn't have much time, actually we didn't get the budget that we thought... To solve the issue by 2018, the team had 3-4 different ideas and made very fast tests".

The intelligent design of the Kaisa Library was also regarded as one of the most impressive projects. Kaisa Library was completed in 2012 as University of Helsinki's new library building. The new library services went through a thorough service design development process where a set of new customer oriented library services was invented together with the users, staff, and stakeholders. The goal of the project is to reform and standardize services and create a coherent service concept that can be easily implemented at all campus libraries [27]. The essence of project is about 'how you design the library services, so that it's really easy for the user' (Interviewee \#1). Interviewee \#5 also noticed that the library created several focus groups looking at different aspects for the library, and made the library staff part of the process to create a feel of ownership. The library service is thus improved due to the 
realisation of the concepts of service design, design thinking, and co-design. Third, the Citizen Service Centre in Espoo is another impressive and massive project, notice by Interviewee \#4. Many cities are currently considering multi-purpose service centres. Iso Omena is a pilot civic service centre in Espoo City. The core idea is to combine spatial planning and service models and find common service commitments and visions for different providers, including libraries, health clinics, child health centres, city service departments, and youth services [27]. According to Interviewee \#4, one unique point of this project is that city designers were invited in the middle of the process, when everything was already functioning. The task is to figure out what was not functioning and what could be the contribution of city designers. City designers brought users' points of view into the conversation by creating a common sense and worked out to assemble the service of different organizations. Overall, the value of the DDC programme is helping to save the whole 2012 WDC project. As described by Interviewee \#6, "it was saved by the initiative, by the organization itself that it carried further... Without that legacy plan, I think people, the residents, the taxpayer, and all the institutions taking part in the 2012 WDC would have reasons to be more disappointed".

DDC ended at the end of 2015. It was replaced by the nomination of Chief Design Officer (CDO). Helsinki is one of the first cities in the world to employ a CDO. The goal is to use design knowledge to strengthen experimental culture. The new $\mathrm{CDO}$ is responsible for a new three-year project called the Helsinki Lab, with the purpose of strengthening users' understanding and experimental culture. The Helsinki Lab aims to make design knowledge, digitization, and interaction an integral part of urban development [28]. According to Interviewee \#3, the CDO's role is to make user-oriented thinking a part of all activity. The CDO has three roles. First, CDO needs to provide the city with creative thinking, with users as priority. Secondly, the position of $\mathrm{CDO}$ also includes strengthening the image of Helsinki as an international design city and developing an international design network. Third, the CDO post shows that Helsinki not only talks about design, but also really uses design to create a better city. Different from the DDC project, which is a kind of bottom-up approach, the initiative of $\mathrm{CDO}$ is more top-down, trying to move up to the top and having more political influence. As stated by Interviewee \#2, "it is very important that CDO sets in the mayor's office ... it's really high up in the hierarchy".

\section{Legacy Outcomes}

\subsection{Integration of Design into Public Administration}

Several interviewees proposed that the most significant legacy of the 2012 WDC was to introduce design into the public sector, and how the city of Helsinki implemented design thinking and education. For instance, Interviewee \#2 explained what design thinking means in the Helsinki city organisation, and said: "design thinking means that all city officers share the customer-the city resident-and they seek to understand the customer's needs and wishes. Second, citizens are included in the planning of services on the principle of co-design, as the Helsinki Central Library project has done. Third, the city adopts an experimentation culture, as the Youth Department has done in seeking a solution to youth homelessness. Fourth, the city applies visualisation to tackle complex issues. All four of the approaches are united by one factor: human orientation". Interviewee \#1 mentioned that City of Helsinki is a very big organization, with 40,000 employees. The 2012 WDC transformed only a very small part of the ship. How to make people rethink from customers' or citizens' perspectives is a very slow movement. However, due to the WDC and its legacy plan, people could see that things are changing. During the theme year, around 50 core people worked for the city administration, started a new angle, and accelerated the movement. Interviewee \#1 took health care service as an example and said: "if we can, through better service design, reduce waiting time, or reduce visits to the health care centre, they have a direct impact on our citizens' quality of life. We're really using design methods all over the city more and more. And these all started during the WDC year. Without that legacy plan, I don't think this movement, this change would have taken place, but slower that is happening now". Interviewee \#7 
also noticed: "the strongest legacy would be the public sector design, and how we are constantly using more and more design, either its design tools, methods, or design thinking, or design education".

\subsection{Embedding Design Thinking}

More than one third of the interviewees believed that the biggest long-term impact of 2012 WDC is 'design thinking'. For instance, Interviewee \#2 said: "the WDC was a very, very future-oriented project, we were not making, we were not talking about the past and history but talking about the future and making that future visible. And then another thing is to make it understandable that design is more than the tangible object, that design is actually the way of thinking". Interviewee \#8 also highlighted that the understanding of design in society has been broadened significantly, among citizens and among companies. "Design is not something that designers doing in their ivory towers, rather it is something that is done together with people" (Interviewee \#8). However, Interviewee \#2 criticised that, in this aspect, Helsinki didn't do it enough well during the WDC year. "The goal succeeded quite well as part of the DDC, namely making it concrete what design thinking actually means" (Interviewee \#2). To continue the momentum, Helsinki continues the corporation with Helsinki Design Week, as part of its program every year. Interviewee \#2 concluded that: "design thinking is no more a project now. It's a permanent way of developing Helsinki, that's the biggest result. Even though it started like as a theme year, as a project, but we don't call it a project anymore. Design is like the DNA of the city now".

\subsection{Enhancement of City Image}

Finland has been regarded as a design country for a long time. Several interviewees believed that the 2012 WDC absolutely reinforced the awareness of Helsinki's city brand. For instance, Interviewee \#8 said: "promoting the national brand of Finland as a pioneering country in design, and networking with other cities in the world" is one of the most sustainable impacts. Interviewee \#1 also believed that the international media coverage during 2012 became the best tool for city branding, and design was used as an element for tourism promotion, for instance, highlighting design-related events and attractions in the official website and travel brochures. However, the majority of respondents expressed reservations about the impact of the 2012 WDC on tourism growth. According to Interviewee \#9, the WDC has definitely boosted the number of visitors in 2012, but in recent years the growth of Helsinki sightseeing has not always been due to the 2012 WDC. "Although Helsinki or Finland is well known for its design, it is difficult to assert that design is the main cause of visitor visits" (Interviewee \#9). In other words, design is an important Helsinki brand, but not the only one. Interviewee \#10 also believed that it is difficult to make such an inference as to whether the number of tourists in the WDC could be increased in 2012, as there are too many factors influencing the number of visitors. Similarly, Interviewee \#11 thought that, although Finland's design is world-famous and Helsinki has a high percentage of visitors to the design museum, it is difficult to assert that design is the deciding factor for visitors.

\subsection{Reinforcement of Networking}

An important result of the WDC Helsinki has been the development of new forms of cooperation in and between different sectors. Helsinki Design Week and Helsinki Design District are two prominent examples. When Helsinki bid for the 2012 WDC title, the annually held Helsinki Design Week was undoubtedly one of the main reasons for success. Interviewee \#7 believed that, in addition to creating a new customer base for Helsinki Design Week, the 2012 WDC strengthened the cooperation between Helsinki Design Week and other institutions in the city (such as universities and museums), and obtained more government grants. While mentioning the linkage between Helsinki Design Week and 2012 WDC, Interviewee \#8 also noticed that Helsinki Design Week was very successful in using the WDC to build an international network. To sum up, the Helsinki Design Week, which started in 2005, helped Helsinki to win the 2012 WDC bid. The latter then contributed to the sustainable development of the former. Now, Helsinki Design Week is working hard to establish the so-called 'World Design 
Weeks' network, with members including Helsinki, Barcelona, New York, San Francisco, Mexico City, Seoul, Tokyo, and Beijing. Interviewee \#7 emphasised "Helsinki is a design city. Helsinki Design Week is a permanent part of the image of Helsinki. If there were no Helsinki Design Week, probably the whole investment for 2012 could have been in question". However, not all the networking built could be attributed entirely to the title year. For instance, partnerships between businesses within the Helsinki Design District existed before 2012.

\subsection{Design Policy Formulation}

Finally, 2012 WDC contributed to the formulation of a design-based policy. According to Helsinki's Strategy programme 2013-2016, the main design related statements that the city commits to are: (a) strengthening Helsinki's position as a major design city by utilising design and design-led thinking in the renewal of the city and in the development of services; (b) design and design-oriented events are used in the city marketing to differentiate Helsinki; and (c) a user-oriented service design is utilised, and the know-how in service design is improved [23].

\section{Legacy Planning: Key Factors and Challenges}

\subsection{Leadership in Governance}

Most of the interviewees attributed the success of 2012 WDC and its legacy plan to the leadership and vision of the Mayor-Jussi Pajunen. "Our mayor is really a visionary and a very wise man, and I had a great respect for him" (Interviewee \#1), Mayor Pajunen led the mayor's office to promote the design of the public sector and to make the offices work together. Since the WDC was directly supervised by the mayor's office, and enforced by the core office-the Department of Economic Development, which is one of the three core departments of Helsinki Municipal Government. Interviewee \#2 believed that Mayor Pajunen played a key role in driving the 2012 WDC and its legacy plan. The mayor thought that the WDC has given the Helsinki city government an 'excuse' to do things in different ways, an experimental spirit. The DDC is another excuse for the city government to continue the 2012 WDC experiment. Interviewee \#7 also pointed out that the key factor is the mayor's leadership and determination, as is a change to give a 'license' in general. In fact, the city has many innovative civil servants, but the mayor's concession seems to be a shot in the arm to support all innovative initiatives. In addition to Mayor Pajunen, Interviewee \#2 pointed out that the main driver behind the DDC is the Secretary General of International Design Foundation-a very visionary and executive woman. She proposed the legacy plan to the city very early. In fact, $\mathrm{CDO}$ and other strategic planning are mostly her idea.

\subsection{Communication with Public}

Interviewee \#3 said that for a long time, design referred to the design of products and buildings, but now design is widely defined as a strategy to achieve a better city. While design can be used to create a new and better solution to meet the needs of society, new concepts such as service design, social design, and design thinking are more difficult to understand and accept for the general public, and good communication strategies are thus a key for success. Interviewee \#2 emphasised that 'Design Stories from Helsinki' is a very effective communication strategy. As the focus of DDC is on the public sector, if only a few projects are being promoted, the level of public awareness is bound to be very low. It was decided to establish a website and electronic publication of the 'Design Stories from Helsinki' via e-marketing in 2015. The Foundation invited professional journalists to scrutinize the projects and write a series of design stories from the perspective of the general public. That is, for those who do not understand the design or do not understand the potential function of the design. This project, executed by the International Design Foundation and supported by the City Marketing Office of the Department of Economic Development, produced a surprisingly positive effect. In the future, 
after the dissolution of the Foundation, the Department of Economic Development will continue this communication strategy (Interviewee \#2).

\subsection{Timing and Time}

Interviewee \#8 believed that Helsinki has undergone a long history of design development before bidding for the 2012 WDC, and may not be as successful if it were to be done in 2008 or 2010. In other words, organizing a large event at the right time will affect the overall effectiveness and impact of the event. In addition, Interviewee \#8 noticed that many cities see the WDC as a one-time promotional event rather than as a 'starting point' or as part of a long-term change process. In fact, "the host city needs to be forward-thinking, thinking about the next 2 years, 5 years, or even 10 years, and ready for a legacy plan" (Interviewee \#8). Since the main purpose of the 2012 WDC is to broaden people's understanding of design and the use of design at all levels of society, it should take many years to achieve it. From the Helsinki case, it took time and could not be achieved in one go. However, most politicians need to see immediate results, and it is difficult to commit for long-term planning (either resources or organizations). Interviewee \#8 pointed out finally that "I think very important is to look ahead, prepare for long term process, have an organization, and have resources, and then you can expect that something will happen. These are big things. If you want to have an impact, you have to think big and not that we get more nice objects".

Apart from the positive opinions, there were also worries about the DDC project revealed during the interviews. For instance, Interviewee \#4 mentioned that the short time-span (only two years) of the legacy plan is the major challenge. It took time to choose appropriate projects, apply for funding and negotiation and implement the plan. To highlight the concept of 'co-design', people also need to open the design process to the public, and require, naturally, a lot more time. Interviewee \#4 said: "sometimes I feel that I am a 'social worker' because in the beginning of almost every project, it was something about talking, about socializing, about open peoples' mind to the possibility of something new... The progress of DDC was therefore very slow". Moreover, some idea created during the DDC project remains unclear. There are still many projects staying in planning level. The second concern is that whether the projects can be sustained after the deadline.

\section{Conclusions}

The increasing importance of major events has led to increasing interest in the concept of sustainability and legacy in host cities. Sustainability requires long-term planning, and the legacy of events has changed from an unknown result to something that should be considered and planned at an early stage [3]. When Helsinki won the bid of WDC, one major vision was to use the WDC as a catalyst for change and leave a legacy benefiting the whole city. The paper is concluded by discussing the empirical and theoretical implications of current study.

\subsection{Key Lessons Learned}

In this paper we discuss the strategy of Helsinki becoming a design-driven city in the aftermath of the 2012 WDC. The strategy responds to several changes in urban policies and regional innovation initiatives. The experience of Helsinki illustrates that legacy planning must involve the following three key factors so as to create more sustainable longer-term effects.

First, 'governance', including political commitment, delivery organisation, adequate resources, and a range of partner organisations, is the prerequisite of any successful legacy plan. In Helsinki, the continuation of a dedicated agency-International Design Foundation-is one way by which a positive legacy can be ensured. International Design Foundation is run by personnel with necessary management skills and experience, financially supported from national and city governments, and has a degree of autonomy from the bureaucratic process. According to Richards and Palmer [1], depending on the specific circumstances of each city, the agency may need to focus entirely differently on the events, perhaps with a different structure and staff. However, such an agency can continue to advance 
some of the activities and take advantage of new opportunities to help ensure that the overall vision of the event is realised in the long run [2]. It is also important to ensure that the major design organisations of the city are fully committed to and participate in the development of the project, because they can put forward many ideas and provide project delivery capabilities. The author doesn't have enough evidence to infer whether the legacy plan would be initiated or implemented without the involvement of the Secretary General of IDF and the support of the Mayor. However, one thing can be confirmed is that for long-term sustainability, host cities need to address all the different aspects of sustainability. Economic and social economic sustainability is not enough if the political aspect of an event is questioned [1].

Second, to gain public support and enhance public awareness, 'communication' is crucial. 2012 WDC and the DDC project raised people's awareness about the importance of service/social design, but more investments and efforts are needed to actually change the culture [18]. 'Helsinki Design Stories' is a successful initiative to help raise the profile of the legacy plan, on a regular and on-going basis, and to build up positive relationships with the media. This strategy coincides with the proposition of Holmes et al. [2], who suggest that community opinions need to be carefully managed. Releasing regular positive new stories can keep public's focus on the positive outcomes, so that the legacy plan won't be challenged. Third, 'time' matters in any legacy plan, and sustainability needs to be considered at an early stage and built-in from the outset. Karadakis and Kaplanidou [29] argue that the legacy could only be guaranteed if it is considered during the planning stage of holding an event. According to Evans' [30] on the European Capital of Culture Project, the event itself is not enough to completely change the city. Most important is that the event or project must be part of a long-term vision and policy for design in the city, where the event is just a dot on the line of the long-term progression.

In order to achieve a lasting legacy, Helsinki tries its best to combine WDC with other plans and long-term urban developments. For example, Kaisa Library and Helsinki Region Infosahre are existing plans for Helsinki prior to WDC designation. Moreover, it is important to understand that the WDC is not just a one-off event, but also as a platform to strengthen, define, or initiate more coherent policies and strategies about design. In Helsinki, the legacy plan has been implemented by integrating design into other areas of urban development, such as education and youth housing. It is also crucial to begin the legacy planning from the earlier stages of event process. Since the title year itself is inevitably very busy, the legacy plan cannot leave until the end of the event. Helsinki is one of the few cities that considered the legacy prior to the WDC, so the legacy plan in Helsinki was well-developed by the end of 2012. The experience of Helsinki told us that, during the transitional phase of ending the event, every effort should be made to maintain the delivery agency. It will also require the special working group to start this process as soon as possible and put in appropriate resources. In fact, this may require individuals who are separate from local authorities and have the time and space to develop strategies and to take actions. Although the interviewees are in general positive about the WDC's legacies, they also admitted that there is still a long way ahead in creating a 'design-driven city'. If design is a new strategy of thinking, considerable time is needed to change the minds and attitudes of people.

\subsection{Limitation and Future Research}

The Helsinki experience has contributed to our understanding about event legacy planning; however, it is necessary to reveal the limitations of this paper. Although the factors proposed in the analysis framework are important, one may question the generalizability to other cities. Unfortunately, few WDC cities have implemented legacy programs and systematically provided measures of the outcome of the legacy, so it is unlikely to conduct a comparative analysis at this stage or judge the success or failure of Helsinki. For the case of Helsinki, the reader may speculate that due to the interviewee's professional background they may have the intention to convey the success of WDC 2012 and its legacy plan, resulting in some bias. Longitudinal study is also necessary to identify any gains or 
losses in the long run. This article points out thus some points for future study, such as incorporating more objective data (e.g., incorporating the perceptions of citizens based on a quantitative/objective research), longitudinal data, examining other practices of event legacy planning, and investigating trends and common issues that influence the sustainability of events.

Funding: This research was funded by the Ministry of Science and Technology of Taiwan grant number MOST105-2410-H-003 -066-MY2.

Acknowledgments: I would like to thank the Ministry of Science and Technology of Taiwan for the grant.

Conflicts of Interest: The author declares no conflict of interest.

\section{References}

1. Richards, G.; Palmer, R. Eventful Cities: Cultural Management and Urban Revitalization; Butterworth-Heinemann: Amsterdam, The Netherlands, 2010.

2. Holmes, K.; Hughes, M.; Mair, J.; Carlsen, J. Events and Sustainability; Routledge: London, UK, 2015.

3. Edizel, H.Ö. Governance of Sustainable Event-led Regeneration: The Case of London 2012 Olympics. Ph.D. Thesis, Brunel University, London, UK, April 2014.

4. Gratton, C.; Preuss, H. Maximizing Olympic impacts by building up legacies. Int. J. Hist. Sport 2008, 25, 1922-1938. [CrossRef]

5. WDO. World Design Capital. 2018. Available online: http://wdo.org/programmes/wdc/ (accessed on 2 April 2018).

6. Liu, Y.D. Quality of life as event legacy: An evaluation of Liverpool as the 2008 European Capital of Culture. Appl. Res. Qual. Life 2017, 12, 653-670. [CrossRef]

7. Matheson, C.M. Legacy Planning, regeneration and events: The Glasgow 2014 Commonwealth Games. Local Econ. 2010, 25, 10-23. [CrossRef]

8. Cashman, R. The Bitter-Sweet Awakening: The Legacy of the Sydney 2000 Olympic Games; Pan Macmillan: London, UK, 2006.

9. Chappelet, J.; Junod, T. A tale of 3 Olympic cities: What can Turin learn from the Olympic legacy of other Alpine cities. In Proceedings of the Major Sport Events as Opportunity for Development, Valencia, Spain, 2006; pp. 83-90.

10. Preuss, H. The Conceptualisation and measurement of mega sport event legacies. J. Sport Tour. 2007, 12, 207-228. [CrossRef]

11. Preuss, H. The contribution of the FIFA World Cup and the Olympic Games to green economy. Sustainability 2013, 5, 3581-3600. [CrossRef]

12. Gold, J.R.; Gold, M.M. "Bring it under the legacy umbrella": Olympic host cities and the changing fortunes of the sustainability agenda. Sustainability 2013, 5, 3526-3542. [CrossRef]

13. Gaffney, C. Between discourse and reality: The un-sustainability of mega-event planning. Sustainability 2013, 5, 3926-3940. [CrossRef]

14. Perić, M.; Đurkin, J.; Wise, N. Leveraging small-scale sport events: Challenges of organising, delivering and managing sustainable outcomes in rural communities, the case of Gorski kotar, Croatia. Sustainability 2016, 8, 1337. [CrossRef]

15. Negruşa, A.L.; Toader, V.; Rus, R.V.; Cosma, S.A. Study of perceptions on cultural events's sustainability. Sustainability 2016, 8, 1269. [CrossRef]

16. Koutrou, N.; Pappous, A.S.; Johnson, A. Post-event volunteering legacy: Did the London 2012 Games induce a sustainable volunteer engagement? Sustainability 2016, 8, 1221. [CrossRef]

17. Liu, Y.D. Event and community development: Planning legacy for the 2008 European Capital of Culture, Liverpool. Urban Sci. 2017, 1, 39. [CrossRef]

18. Otgaar, A.; Carvalho, L. World Design Capital: Helsinki. In Delivering Sustainable Competitiveness: Revisiting the Organising Capacity of Cities; Carvalho, L., van den Berg, L., Galal, H., Teunisse, P., Eds.; Routledge: London, UK, 2016; pp. 200-218.

19. Holstila, E.; Vallittu, A.; Ranto, S.; Lahti, T.; Manninenm, A. Helsinki. In Cities as Engines of Sustainable Competitiveness: European Urban Policy in Practice; van den Berg, L., van der Meer, J., Eds.; Routledge: London, UK, 2016; pp. 175-189. 
20. City of Helsinki. Strategy Programme 2009-2012; City of Helsinki: Helsinki, Finland, 2009.

21. Berglund, E. Activist design in Helsinki. In Creative Capitalism, Multitudinous Creativity, Radicalities and Alterities; Cocco, G., Szaniecki, B., Eds.; Lexington: London, UK, 2015; pp. 155-171.

22. Focus Finland. How to Design a City? Focus Finland: Helsinki, Finland, 2012.

23. City of Helsinki. Application UNESCO Creative Cities Nomination. Available online: https://www.hel.fi/ static/kanslia/elo/Application_Unesco_Creative_Cities_Nomination_City_of_Helsinki.pdf (accessed on 2 April 2018).

24. Deloitte. World Design Capital 2012: Embedding Design in Life; Deloitte: Helsinki, Finland, 2013.

25. Icsid. The Lasting Legacy of WDC Helsinki 2012. Available online: http://www.icsid.org/feature/current/ articles2062.htm (accessed on 2 April 2018).

26. City of Helsinki. City Driven by Design: Design Thinking Assumes Permanent Role in Helsinki's Development. Helsinki News. March 2015. Available online: www.hel.fi/static/helsinki/news/engla nti/Helsinki-News-03-2015.pdf (accessed on 2 April 2018).

27. City of Helsinki. Design Stories from Helsinki. Available online: https://www.muotoilutarinat.fi/en (accessed on 2 April 2018).

28. Helsinki Design Week. City of Helsinki among the First in the World to Hire CDO. Available online: http:/ / www.helsinkidesignweek.com/weekly/ city-of-helsinki-among-the-first-in-the-world-to -hire-chief-design-officer (accessed on 2 April 2018).

29. Karadakis, K.; Kaplanidou, K. Legacy perceptions among host and non-host Olympic Games residents: A longitudinal study of the 2010 Vancouver Olympic Games. Eur. Sport Manag. Q. 2012, 12, 243-264. [CrossRef]

30. Evans, G. Cities of Culture and the Regeneration Game. Ph.D. Thesis, Brunel University, London, UK, 2011.

(C) 2018 by the author. Licensee MDPI, Basel, Switzerland. This article is an open access article distributed under the terms and conditions of the Creative Commons Attribution (CC BY) license (http:/ / creativecommons.org/licenses/by/4.0/). 